\title{
A tradição do riso
}

\section{Maria Thereza Vargas}

alvez a maneira mais simples de refletir sobre a tradição do teatro brasileiro seja pensar na origem da palavra tradição. Tradição vem de traditio, que significa transmitir aquilo que nos é transmitido ao longo dos tempos, aquilo que liga o passado ao presente. Alguns dicionários dizem até mais. Explicam tradição como entregar, dar alguma coisa. Há também uma poética ligação da palavra tradição com a palavra memória. No caso dessa ligação, que une passado ao presente, o que me vem à mente é a vocação tremenda do teatro brasileiro para o riso. $\mathrm{O}$ riso provocado pela comédia pura e simples, o riso da farsa, o riso da revista do ano, do musical, da comédia de costumes, fruto às vezes de observaçóes sofisticadas, como era o caso dos textos de Silveira Sampaio, fruto às vezes das observações simplórias, corriqueiras, suburbanas de um Gastão Tojeiro.

Não deixa de ser impressionante o fato de que, no mesmo dia em que Tiradentes era executado, o Senado da Câmara do Rio de Janeiro concedia licença para que um bando de histriões anunciasse para aquela noite uma apresentação em praça pública. "Eram três as figuras principais", diz a crônica, "o primeiro vestido de Arlequim e os outros dois enfronhados em negras camisolas burlescamente sarapintadas, tendo à cabeça longos chapéus afunilados”. Desconfiam os cronistas tratar-se de uma adaptação de alguma comédia de Molière, muito em moda na época.

Oficialmente começamos a rir com Martins Penna e suas comédias de costumes apontando ao povo problemas que realmente existiam em volta dele: o inglês astuto se aproveitando da boa fé ou da ignorância do brasileiro, os juízes incompetentes, o problema da moradia, as esmolas em proveito próprio tiradas pelos irmãos das almas.

Quando pensamos em José de Alencar no teatro, o que nos vem de pronto é $O$ Demônio Familiar e seu personagem Pedro, escravinho cujo maior desejo é ser cocheiro de patrão rico. Com esse intuito, leva a família e os amigos ao maior rebuliço, com suas mentiras e intrigas. Mas é apoiado nessa figura não trágica (inconseqüente como todo pícaro) que José de Alencar consegue fazer passar ao público, como observa o professor Décio de Almeida Prado, "uma longa reflexão sobre a sociedade brasileira, suas contradições e a necessidade urgente de uma unificação moral e social".

Arthur Azevedo, na maioria das vezes, se faz acompanhar da música. Sua graça vem do

Maria Thereza Vargas é pesquisadora de teatro brasileiro. 
trocadilho, da réplica pronta, do humor português mesclado ao humor carioca, da mais profunda identidade com sua cidade e seu povo. A graça já está mesmo contida nos títulos. Quando o Rio de Janeiro, por influência francesa, está no auge da invasão das operetas, Azevedo traduz os títulos pelo som: La fille de Mme. Angot passa a ser $A$ filha de Maria Angu, La belle Hélène torna-se Abel, Helena.

A comédia sustentou o teatro brasileiro após a Primeira Grande Guerra e eu diria que se agüentou até a sua maioridade. Começamos a nos encantar pelo campo e seus sabiás, sorríamos com visóes paradisíacas, longe de qualquer possibilidade de crise. São abandonados os ingleses ou falsos ingleses com suas invenções absurdas e entram em cena os tipos brasileiros que vão à Europa e voltam encantados por Paris, falam francês e olham com desdém a pátria e seus compatriotas. E no terceiro ato, rendem-se à singeleza das mocinhas, aos sabiás, à beleza da Guanabara. Mas o que faz sucesso mesmo são os empregados e empregadas (sempre os pares), que entre patriotadas e sentimentalidades encarregam-se dos entremeados cômicos.

Ao se aproximarem os anos trinta, as empregadas, sempre com seus espanadores na mão, passam do subúrbio ao centro. A consagração do tipo é sem dúvida a Etelvina da peça Cala boca, Etelvina, escrita por Armando Gonzaga em 1925. Não mais escrava - pelo menos segundo a lei - é dona da situação, e se provoca encrenca é porque foi obrigada pelo patrão a passar por madame a fim de salvar uma situação difícil. É de Etelvina, sem dúvida, que descende a Floripes de Em moeda corrente do pais, de Abílio Pereira de Almeida e, mais recentemente, a Fulaninha de Noemi Marinho.

Essa empregada dominou a comédia, a farsa e a revista por muitos e muitos anos. E se hoje se encontra um tanto esmaecida é porque a comédia utiliza-se sempre do muito presente, e empregadas hoje são raras. (Um pequeno parênteses para lembrar que Sílvio de Abreu, como bom aluno de dramaturgia, fez na novela Torre de Babel uma pequena homenagem a essa criada, como era chamada. É Luzineide, com seu uniformezinho e espanador, mas agora simbolicamente muda...)

Não poderemos nos esquecer que foi através da comédia de costumes que o público de São Paulo entrou em contato com uma dramaturgia paulista mais atualizada. Seu criador foi Abílio Pereira de Almeida, autor com um senso de observação muito apurado, qualidade sem dúvida primordial para um bom comediógrafo, mas infelizmente não a única. Se faltou-lhe maior profundidade no tratamento, não nos esqueçamos que teve o mérito de fazer sua própria classe rir de si mesma e nós que não pertencíamos àquele mundo, contemplarmos, com a curiosidade superior de público de comédia, os "pif-pafs" e suas conseqüências, as espertezas das telefonistas do Automóvel Clube, os dúbios ideais dos industriais na revolução paulista de 1932.

O sucesso desse autor, quando se apresentou pela primeira vez em 1946, foi muito grande. Conseguiu lotar - é bem verdade que era um teatro feito às segundas-feiras - o Teatro Boa Vista, um teatro pequeno, mas construído à moda antiga, com platéias, frisas e torrinhas. $\mathrm{E}$ tudo isso provocado por um riso que São Paulo moderno ainda não conhecia por conta própria. Ríamos até então das graças cariocas trazidas por Procópio, Jayme Costa ou Alda Garrido.

Foi incorporando figuras risíveis dos espetáculos populares que Ariano Suassuna nos apresentou sua grande obra poética, transformando as figuras - que conhecíamos dos barros de Vitalino e vagamente dos mamulengos - em espertos cheios de esperança, desconfiados do imenso valor de sua existência. Com seu auxílio, explorando sua graça e esperteza, pode construir no palco um vasto painel de esperanças. (Tenho a impressão de que o riso traz a esperança. $\mathrm{Na}$ minha opinião, os dois maiores dramaturgos brasileiros são Nelson Rodrigues e Ariano Suassuna. Mas um é o dramaturgo da desesperança e o outro é o da esperança. Daí o riso contrafeito provocado pelos personagens de Nelson.)

Se o riso intrometeu-se entre os católicos, não deixou de emprestar sua força aos drama- 
turgos da esquerda. Vianninha utilizou-se dele não só para driblar os maus tempos, mas também para dar expressão dramática àquilo que the era peculiar, àquilo que nascia como um dom mais profundo de sua maneira de ser. A silhueta de Roque, personagem de Se correr o bicho pega, se ficar o bicho come, percorre o nosso teatro. Assim como Fulaninha descende de Etelvina, dando uma certa empurradinha Roque tem alguma coisa do Pedro de $O$ demônio familiar. Seu caráter ressente-se de uma definição. Serve a dois senhores, e se for preciso a três. Não tem ainda o discernimento para uma atuação consciente.

Segundo Vianinha, a literatura popular o cordel, no caso - traz com ela a intuição da arte dramática como uma manifestação de encantamento, de invenção. E isso torna a dramaturgia comprometida muito mais leve, artística, criando a distância para a compreensão.

Nossos autores, ao tomarem conhecimento de Brecht, perceberam logo o quanto o dramaturgo alemão reconhecia e fazia uso do potencial didático da comédia. Personagens burlescos, música (paródias maliciosas ou simplesmente espirituosas), a réplica pronta a ser dada, o emprego do verso popular, não deixaram de ser instrumentos poderosíssimos na construção dessa dramaturgia desejosa de transformaçôes.

Juca de Oliveira, Jandira Martini, Marcos Caruso, com seus dois espetáculos há mais de ano em cartaz (Caixa 2 e Porca miséria), ajudam nossa reflexão. "A comédia é um gênero teatral que trata dos defeitos humanos e os homens estão muito mais defeituosos hoje do que ontem" - são palavras de Juca, justificando a forma que seu texto tomou. Em suas comédias, os caracteres genéricos vão encaminhando e esclarecendo o tema. A graça provém do significado da história contada. Sua importância é que revisita a velha comédia paulista, na qual a presença do imigrante italiano era fundamental. Reporta-se ao Castagnaro da festa, de Oduvaldo Vianna, aos textos escritos especialmente para o ator Nino Nello, um cômico ítalo-paulista. Nelas, os títu- los falam por si: Dom Gaetano Mangiaferro; Italiano com muita honra; Um baile no Canindé; Filho de sapateiro, sapateiro deve ser.

Porca miséria necessita do ator cômico, com toda a força de sua individualidade. Dois de seus intérpretes foram autores também dos textos, o que reforça a comédia com o golpe certeiro do ator-autor. A presença de Myriam Muniz, atriz de origem italiana, com todos os sabores de sua descendência possibilitou a criação em cima de uma verdade incontestável.

O certo é que este tipo de comédia repousa sobre o intérprete. Dar vida a essa espécie de riso não é para qualquer um. Tanto a farsa quanto a mais sutil comédia teve seus atores ideais, homens e mulheres que conhecem de sobra as complicações da vida e, por outro lado, a sua efemeridade. Vasques, Brandão, Ítala Ferreira, afivelaram a máscara da comédia, como diziam os literatos antigos. Procópio fez do riso a sua profissão de fé. Para provar sua teoria da supremacia do riso, chegou mesmo a jogar o ator Vasques contra João Caetano. Para ele, João Caetano era um fracasso. Para ter público, sugeriu a proibição de espetáculos circenses nos dias de suas apresentaçôes. Grande mesmo, diz ele, era o Vasques, que conseguia levar público ao teatro. Seu Orfeu na roça conseguiu cem representações num Rio de Janeiro de três mil habitantes.

O primeiro ator brasileiro de que temos notícia é lembrado pelos seus "gatimanhos e trejeitos”. Trata-se do índio Ambrósio Pires, citado pelos jesuítas num comunicado à Ordem, narrando uma festa de recepção. Surgia do meio da mata, como Anhangá, o diabo. Encantou e fez rir os presentes. Os "gatimanhos e trejeitos" de Ambrósio por acaso não se aproximam da descrição que nos fez Souza Bastos quando falou do ator Brandão? "Faz coisas extraordinárias, mas que ao seu feitio não ficam mal. Enterra o chapéu até as orelhas, (...) esbugalha os olhos, escancara a boca, grita, gesticula exageradamente; mas tudo que era insuportável noutro, nele fez-nos rir a valer. De mais a mais improvisa, e por vezes com felicidade". 
Foi contra essa força do riso que em certas épocas algumas vozes se levantaram. Todos nós nos lembramos das palavras de Arthur Azevedo: "Não é a mim que se deve o que o Sr. Cardoso da Motta chama o princípio da débâcle teatral; não foi minha (nem de meu irmão, nem de quelqu'un des miens (...) a primeira paródia que se exibiu com extraordinário sucesso no Rio de Janeiro". Não fui eu, nem meu irmão, nem nenhum dos meus o causador da derrota do teatro nacional".

É que - parodiando o professor Eudinyr Fraga - o nosso teatro tem sempre uma espécie de nostalgia da seriedade. E curiosamente - e isto também é uma tradição - eram sempre os amadores e os estudantes que velavam pela sua compostura. Foi assim com o Teatro do Estudante do Brasil e seus Shakespeares, com Os Comediantes, com os grupos paulistas - a segunda fase do Arena - e o Teatro Oficina, nascido das Arcadas.

Adolfo Celi, ao chegar ao Teatro Brasileiro de Comédia em 1949, declarou: "seria desejável começar pela farsa, capaz de fazer rir e pensar". Deu uma olhadela em volta e percebeu que havia sido inconveniente. Rapidamente mudou o tom: "Gostaria de montar um Kaiser e fazer Ricardo III". 